\title{
Implementation of Self-Management Interventions in Cancer Survivors: Why Are We Not There Yet?
}

\author{
Ben $\operatorname{Rimmer}^{1}$ (1) $\cdot$ Linda Sharp ${ }^{1}$ - on behalf of Ways Ahead study team
}

Accepted: 25 April 2021/Published online: 2 May 2020

(c) The Author(s) 2021

\begin{abstract}
Despite the growing evidence base for supported self-management for the improvement of quality of life, there is a lack of widespread implementation of self-management interventions for cancer survivors. We propose five key areas that, if addressed, would optimise the development and evaluation of these interventions, namely: (1) improving intervention adaptability to different survivor populations; (2) establishing intervention acceptability (and feasibility); (3) ensuring systematic description of interventions, their content, and active ingredients; (4) conducting process evaluations; and (5) assessing cost-effectiveness. These areas are an essential prerequisite for translation of self-management interventions from research into routine cancer care.
\end{abstract}

Keywords Self-management · Cancer $\cdot$ Survivorship $\cdot$ Interventions

\section{Introduction}

Self-management is an individual's awareness and active participation in their recovery, recuperation, and rehabilitation, to minimise treatment consequences and promote survival, health, and wellbeing. There is a growing evidence base suggesting that self-management interventions can improve various clinical, psychosocial, and economic outcomes - including quality of life, physical and psychological wellbeing, and healthcare utilisation - in people with cancer [1]. This is particularly true for supported selfmanagement, as health professionals, family and friends, and fellow patients are instrumental to a patient's ability to manage their condition [2].

However, although supported self-management is a key focus of cancer strategies and plans in some countries (e.g. UK and Australia), self-management interventions have not generally been adopted into routine practice. For example,

Members of the Ways Ahead study team are listed in acknowledgements.

Ben Rimmer

ben.rimmer@newcastle.ac.uk

1 Population Health Sciences Institute, Newcastle University Centre for Cancer, Newcastle University, Ridley Building 1, Newcastle upon Tyne NE1 7RU, England, UK when researchers tried to roll out Oncokompas, under a third of eligible sites adopted it [3]. This may be because it is unclear what implementation approaches and changes to care pathways are necessary to support and embed selfmanagement interventions. However, beyond this, there are several areas, which, if addressed, could optimise the development, evaluation, and, consequently, implementation of self-management interventions.

\section{Adaptability}

Self-management interventions have typically been developed for survivors of a specific cancer, often breast cancer [1], or involved mixed groups of survivors. Cancer is a complex chronic illness, meaning a 'one size fits all' approach is not appropriate. For example, (at least some of) the selfmanagement needs of young adult survivors of childhood cancer, at risk of long-term cardiovascular disease; middleaged people with a life-limiting glioma, experiencing seizures; and older men with urinary problems following prostate cancer treatment may be very different. Conversely, for many cancers, survivors may struggle to adjust to their new normal and may benefit from support to self-manage issues around healthcare, treatment, distress, and re-establishing social roles. 
Behaviour change interventions targeted to a specific population, which are personalised and tailored to individual needs, are more likely to be effective [4]. Hence, it is important to understand and encompass the needs of specific cancers during intervention development. These needs are likely to change over time, so what is needed to self-manage soon after initial treatment and in the longer term may be different. Still, targeted, tailored, and personalised interventions for individuals with different cancers at different timepoints are at tension with the idea of widespread adoption and implementation across routine cancer care.

A self-management programme that is adaptable or flexible across people, cancers, and time may be more attractive to implement. But how might this be achieved? Selfmanagement interventions are typically either adjustment- or problem-focused. Adjustment-focused interventions aid the general transition to survivorship by teaching self-management skills, such as problem solving, goal setting, action planning, healthcare communication, motivation, and confidence [5]. Problem-focused interventions enhance the survivor's capability to manage specific cancer-related issues, such as pain and fatigue. An adaptable self-management programme could address both adjustment and problems, perhaps with 'core' elements around adjustment that apply across cancers and targeted problem-focused elements for cancer-specific needs. Development need not start de novo; rather, it may be possible to adapt existing effective interventions for content and context [6].

\section{Acceptability}

In research studies, cancer survivors generally report a high perceived need for, and positive attitude towards, selfmanagement [7]. However, without evaluation in 'routine practice', it is unclear whether interventions are widely acceptable. Trial participants are often highly selected, so what is acceptable to them may not be generalisable. Consequently, testing in diverse 'real world' survivor populations is required to ensure widespread acceptability.

Self-management is not, and should not be, the sole responsibility of the survivor. Health professionals have an influential role, as do family members, who often act as informal carers [2]. It is, therefore, crucial to consider how self-management is perceived by those closely involved in the survivor's formal and informal care. Patients may expect health professionals to fulfil a comprehensive role, working together to identify and address support needs. However, health professionals may conceptualise selfmanagement as the patient's responsibility [8] and, even if they view their role positively, may lack training, skills, time, and other resources to actively and routinely support self-management. Hence, addressing — as part of intervention development and testing - acceptability to, and feasibility for, health professionals to facilitate selfmanagement is critical. Family should also be integrated in intervention development. This will help ensure that consequent interventions are acceptable to those who use them, as well as those who deliver and/or support them. It will also facilitate the formation of partnerships between patients, providers, and family, which are needed to enable integration of interventions into cancer care [5].

\section{Description}

Defining the core components and active ingredients of an intervention is critical to ensuring that mechanisms of action (see below) are understood, and interventions are replicable (and/or adaptable by others). Taylor et al. identified five core components of self-management, namely: (1) education about the condition; (2) psychological strategies to support adjustment; (3) treatment adherence support strategies; (4) practical support for daily and cancer-specific activities; and (5) social support [9]. This resulted in the PRISMS taxonomy, a 14-component framework to aid the design and description of self-management interventions [10].

However, few self-management interventions in cancer utilise the same combinations of core components [1], with a variety of components identified [11]. For many interventions, what the components comprise is not clearly described. Moreover, less than $50 \%$ of such interventions include a theoretical framework in their development [12], despite theories of social cognition being the basis for selfmanagement. These limitations may help to account for the inconsistent evidence of effectiveness [8] and undoubtedly hinder understanding of what intervention components are (most) effective and, hence, translation into practice.

To enable progress in this area, those who develop interventions should describe the intervention and map the content and postulated active ingredients, using established frameworks, such as TIDiER [13], PRISMS [10], and the Behaviour Change Taxonomy (https://www.bct-taxonomy. com/about). Regarding implementation, this would help inform training and support requirements, so that the delivery of self-management interventions beyond the research context can be improved.

More generally, there is a need to synthesise the evidence from existing interventions to understand what they involve and whether specific features (i.e. characteristics, components, and behavioural change techniques) are associated with efficacy (in a trial context) and effectiveness (in the 'real world'). Systematic intervention description would also support this. 


\section{Process Evaluations}

Process evaluations have a fundamental role in understanding how and for whom interventions do or do not work [14]. However, few, if any, process evaluations of self-management interventions in cancer have been conducted. Thus, evidence is lacking on which intervention components improve outcomes (and by what mechanisms), and the contextual factors that influence this. Likewise, for ineffective interventions, it is unclear whether this is because fidelity was poor, or mechanisms of action were incorrectly specified.

Process evaluations can serve different functions at each stage of intervention development and evaluation. Evaluation at the pilot stage could inform acceptability of implementation, while evaluation at the effectiveness stage might inform the function of different mechanisms [14]. Importantly, the evaluation of each development stage must consider all stakeholders, including survivors, family, health professionals, and commissioners/providers.

\section{Cost-Effectiveness}

Evidence from various chronic diseases suggests that selfmanagement can reduce healthcare resource utilisation [15]. Conversely, implementing self-management support may require the healthcare organisation to provide training, time, and material resources [9].

However, there is limited evidence to indicate whether implementing a self-management intervention into routine cancer practice is cost-effective. Most trials have failed to report any health economic evaluation. In the instance of two interventions, reported cost-effectiveness was not entirely conclusive [11]. A pertinent issue for economic evaluations to date is the short time horizon, as actual costs and benefits are likely to accrue over a long time.

The real-world implementation of a self-management intervention requires a whole-system approach [9]. Evidence on cost-effectiveness and budgetary impact is expectedly critical for policy makers and service providers. Improvements to outcome measures are insufficient if they are marginal compared to operational costs of the intervention.

\section{Conclusion}

Future research on self-management interventions in cancer survivors should consider and incorporate adaptability across people, cancers, and time; acceptability to end users, including survivors, family, and health professionals; systematic descriptions of the intervention, its content, and active ingredients; process evaluations to understand what does and does not work; and evaluation of cost-effectiveness. These are essential for rigorous, systematic, and transparent intervention development, specification, testing, and reporting and are a prerequisite for translation from research into routine cancer care.

Acknowledgements Thanks to Morven Brown and Fiona Menger for their insightful comments on initial drafts of this commentary. The Ways Ahead study team includes both authors and Lizzie Dutton, Joanne Lewis, Richéal Burns, Pamela Gallagher, Sophie Williams, Vera Araujo-Soares, and Tracy Finch (research.ncl.ac.uk/waysahead).

Author Contribution Ben Rimmer wrote the manuscript, while Linda Sharp reviewed and edited the manuscript.

Funding This work is supported by The Brain Tumour Charity, grant number: GN-000435.

Data Availability Data sharing is not applicable to this article as no new data were created or analysed.

Code Availability Not applicable

\section{Declarations}

Conflict of Interest The authors declare no competing interests.

Open Access This article is licensed under a Creative Commons Attribution 4.0 International License, which permits use, sharing, adaptation, distribution and reproduction in any medium or format, as long as you give appropriate credit to the original author(s) and the source, provide a link to the Creative Commons licence, and indicate if changes were made. The images or other third party material in this article are included in the article's Creative Commons licence, unless indicated otherwise in a credit line to the material. If material is not included in the article's Creative Commons licence and your intended use is not permitted by statutory regulation or exceeds the permitted use, you will need to obtain permission directly from the copyright holder. To view a copy of this licence, visit http://creativecommons.org/licenses/by/4.0/.

\section{References}

1. Howell D, Harth T, Brown J, Bennett C, Boyko S (2017) Selfmanagement education interventions for patients with cancer: a systematic review. Support Care Cancer 25(4):1323-1355. https:// doi.org/10.1007/s00520-016-3500-z

2. Dwarswaard J, Bakker EJ, van Staa A, Boeije HR (2016) Selfmanagement support from the perspective of patients with a chronic condition: a thematic synthesis of qualitative studies. Health Expect 19(2):194-208. https://doi.org/10.1111/hex.12346

3. de Wit LM, van Uden-Kraan CF, Lissenberg-Witte BI, Melissant HC, Fleuren MA, Cuijpers P, Verdonck-de Leeuw IM (2019) Adoption and implementation of a web-based self-management application "Oncokompas" in routine cancer care: a national pilot study. Support Care Cancer 27(8):2911-2920. https://doi.org/10. 1007/s00520-018-4591-5

4. Bradbury K, Steele M, Corbett T, Geraghty AW, Krusche A, Heber E, ... Yardley L (2019) Developing a digital intervention 
for cancer survivors: an evidence-, theory-and person-based approach. NPJ Digit Med 2(1):1-13.https://doi.org/10.1038/ s41746-019-0163-4

5. McCorkle R, Ercolano E, Lazenby M, Schulman-Green D, Schilling LS, Lorig K, Wagner EH (2011) Self-management: enabling and empowering patients living with cancer as a chronic illness. CA: a cancer journal for clinicians 61(1):50-62. https://doi.org/ 10.3322/caac. 20093

6. Evans RE, Craig P, Hoddinott P, Littlecott H, Moore L, Murphy S, ... Moore G (2019) When and how do 'effective' interventions need to be adapted and/or re-evaluated in new contexts? The need for guidance.https://doi.org/10.1136/jech-2018-210840

7. Jansen F, van Uden-Kraan CF, van Zwieten V, Witte BI, Verdonck-de Leeuw IM (2015) Cancer survivors' perceived need for supportive care and their attitude towards self-management and eHealth. Support Care Cancer 23(6):1679-1688. https://doi.org/ 10.1007/s00520-014-2514-7

8. Sadler E, Wolfe CD, McKevitt C (2014) Lay and health care professional understandings of self-management: a systematic review and narrative synthesis. SAGE Open Med 2:2050312114544493. https://doi.org/10.1177/2050312114544493

9. Taylor SJ, Pinnock H, Epiphaniou E, Pearce G, Parke HL, Schwappach A, ... Sheikh A (2014) A rapid synthesis of the evidence on interventions supporting self-management for people with long-term conditions: PRISMS-Practical systematic Review of Self-Management Support for long-term conditions. https://doi. org/10.3310/hsdr02530

10 Pearce G, Parke HL, Pinnock H, Epiphaniou E, Bourne CL, Sheikh A, Taylor SJ (2016) The PRISMS taxonomy of self-management support: derivation of a novel taxonomy and initial testing of its utility. J Health Serv Res Policy 21(2):73-82. https:// doi.org/10.1177/1355819615602725
11 Burns RM, Wolstenholme J, Shinkins B, Frith E, Matheson L, Rose PW, Watson E (2017) Including health economic analysis in pilot studies: lessons learned from a cost-utility analysis within the PROSPECTIV pilot study. Glob Reg Health Technol Assess 4(1):grhta-5000269. https://doi.org/10.5301/grhta.5000269

12. Cuthbert CA, Farragher JF, Hemmelgarn BR, Ding Q, McKinnon GP, Cheung WY (2019) Self-management interventions for cancer survivors: a systematic review and evaluation of intervention content and theories. Psychooncology 28(11):2119-2140. https:// doi.org/10.1002/pon.5215

13. Hoffmann TC, Glasziou PP, Boutron I, Milne R, Perera R, Moher D, ... Michie $S$ (2014) Better reporting of interventions: template for intervention description and replication (TIDieR) checklist and guide. Bmj 348.https://doi.org/10.1136/bmj.g1687

14. Araújo-Soares V, Hankonen N, Presseau J, Rodrigues A, Sniehotta FF (2018) Developing behavior change interventions for self-management in chronic illness. Eur Psychol. https://doi.org/ 10.1027/1016-9040/a000330

15. Panagioti M, Richardson G, Small N, Murray E, Rogers A, Kennedy A, ... Bower P (2014) Self-management support interventions to reduce health care utilisation without compromising outcomes: a systematic review and meta-analysis. BMC Health Serv Res 14(1):1-14. https://doi.org/10.1186/1472-6963-14-356

Publisher's note Springer Nature remains neutral with regard to jurisdictional claims in published maps and institutional affiliations. 